- This paper alerts readers to new guidance from the Department of Health for England on consent for school dental inspections and dental epidemiological surveys.

- The implications for those commissioning and undertaking these activities are discussed and comparisons drawn with guidance for obesity monitoring.

- The impact of different approaches to consent on participation rates in a series of epidemiological surveys is examined.

- Results for the last in the series of Somerset surveys begun by Anderson in 1963 are reported.

\title{
Consent and school-based surveys
}

\author{
D. A. White, ${ }_{1}^{1}$ A. J. Morris, ${ }^{2}$ K. B. Hill ${ }^{3}$ and G. Bradnock ${ }^{4}$
}

Possession of information on population health needs is at the heart of the commissioning process.' The move to local commissioning arrangements for all NHS dental services makes this particularly relevant for dentistry. High response rates in surveys are necessary for the results to be sufficiently valid to inform commissioning decisions. Our recent experience in organising and undertaking school-based epidemiological surveys has demonstrated an increasing problem with recruiting subjects of all ages. This has significant implications for dental epidemiological surveys in the future.

School-based screening and epidemiological surveys have traditionally been undertaken using 'negative' consent, where parents or guardians are informed that the exercise is pending and are given the option of excluding their child. The Department of Health re-affirmed the suitability of this approach in 1992: 'It is acceptable to rely on negative consent and tell parents that, unless they express an objection, they will be assumed to have consented to the examinations. ${ }^{2}$

Guidance issued in 2006 by the Department of Health has superseded this; those carrying out school dental inspections and surveys are now required to obtain positive consent from children, or their parents, depending on the age of the child. ${ }^{3}$ The new guidance affirms that older children (10/11-yearolds) would normally be regarded as

\footnotetext{
Senior Lecturer in Dental Public Health, ${ }^{2 *}$ Consultant in Dental Public Health, ${ }^{3}$ Lecturer in Behavioural Science, ${ }^{4}$ University of Birmingham, School of Dentistry, St

Chad's Queensway, Birmingham, B4 6NN

*Correspondence to: Mr A. John Morris

Email:a.j.morris@bham.ac.uk
}

competent to consent to a simple dental examination, but not younger children. Discussions have been held between the Department of Health and the Department for Education and Skills (DfES) to explore how consent for younger children might be obtained from parents or guardians at school entry, backed by the opportunity to withdraw their child at any time. This could potentially minimise the impact of positive consent on participation rates. Unfortunately these discussions have concluded that there is no standard national process for achieving this ${ }^{4}$ and it will be for PCTs to develop local arrangements if they can. Whilst consent is not the only factor affecting participation rates in dental surveys, there are likely to be severe implications for surveys of younger children, which are particularly important for the planning of child oral health promotion initiatives. A NHS survey of five-year-old children is planned for $2007 / 8 .^{5}$

School-based surveys that were not covered by the 1992 guidance have been using positive parental consent for some time. Our experience in a variety of such studies have shown that positive consent has led to increasing difficulty in obtaining an acceptable response rate with an associated increase in adminis- tration costs. When recruiting schools and subjects for surveys, there are a number of stages at which potential subjects might be lost and this applies to both negative and positive consent. Obtaining class lists for sampling, distribution of consent forms to parents and collection of responses all require co-operation from the schools involved. There are several points in this process where the form might go astray, particularly as the child is often asked to take a form home and return it to school. Under negative consent arrangements it has been assumed, perhaps inappropriately, that it is acceptable to examine a child where no form has been returned from the parent or guardian requesting their removal from the study. Positive consent arrangements usually mean that written evidence of consent needs to be available at the time of examination. Obviously, it goes without saying that no child would be examined under either system if they did not want to be. When positive consent is used, however, the children and/ or parents who are equivocal about the study will not be seen, nor will those for whom the form was lost and this may, therefore, have an unbalanced impact on the outcome of surveys or screenings.

From our work, there also appears to 
Table 1 Caries prevalence across the surveys

\begin{tabular}{|l|l|l|l|l|l|l|l|l}
\hline Year of examination & No. Children & $\begin{array}{l}\text { Mean } \\
\text { DMFT }\end{array}$ & S.E. & $\begin{array}{l}\text { n. DMFT } \\
=0\end{array}$ & \% & $\begin{array}{l}\text { n. DT } \\
>0\end{array}$ & \% & FT/DMFT \\
\hline 1963 & 180 & 5.36 & 0.23 & 5 & $2.8 \%$ & 120 & $66.7 \%$ & 0.50 \\
\hline 1978 & 393 & 3.44 & 0.12 & 52 & $13.2 \%$ & 70 & $17.8 \%$ & 0.85 \\
\hline 1982 & 358 & 2.77 & 0.13 & 90 & $25.1 \%$ & 36 & $10.1 \%$ & 0.89 \\
\hline 1988 & 339 & 1.05 & 0.08 & 193 & $56.9 \%$ & 19 & $5.6 \%$ & 0.88 \\
\hline 1993 & 273 & 0.63 & 0.08 & 198 & $72.0 \%$ & 17 & $6.2 \%$ & 0.81 \\
\hline 2004 (1963 criteria) & 202 & 0.47 & 0.09 & 158 & $78.2 \%$ & 5 & $2.5 \%$ & 0.83 \\
\hline 2004 (2004 criteria) & 202 & 0.63 & 0.10 & 141 & $69.8 \%$ & 25 & $12.4 \%$ & 0.62 \\
\hline
\end{tabular}

Table 2 Prevalence of other conditions

\begin{tabular}{|c|c|c|c|c|c|c|}
\hline \multicolumn{7}{|c|}{ Percentages of children with: } \\
\hline $\begin{array}{l}\text { Traumatised } \\
\text { incisors }\end{array}$ & $\begin{array}{l}\text { Tooth wear } \\
\text { affecting } \\
\text { enamel only } \\
\text { or enamel } \\
\text { \& dentine }\end{array}$ & $\begin{array}{l}\text { Tooth wear } \\
\text { affecting } \\
\text { enamel } \\
\text { \& dentine }\end{array}$ & $\begin{array}{l}\text { Teeth } \\
\text { extracted } \\
\text { for } \\
\text { orthodontic } \\
\text { ourposes }\end{array}$ & $\begin{array}{l}\text { Orthodontic } \\
\text { applicance } \\
\text { in place }\end{array}$ & $\begin{array}{l}\text { Incisor } \\
\text { overjet in } \\
\text { excess of } \\
5 \mathrm{~mm}\end{array}$ & $\begin{array}{l}\text { IOTN } \\
\text { Aesthetic } \\
\text { component } \\
\text { score } 6 \\
\text { or greater }\end{array}$ \\
\hline $5.9 \%$ & $46.5 \%$ & $3.5 \%$ & $5.9 \%$ & $9.9 \%$ & $13.9 \%$ & $26.2 \%$ \\
\hline
\end{tabular}

be an increasing issue of parents actively refusing to allow their children to take part, either by withholding a response or by returning a refusal slip. Over the past 10-12 years our involvement with a number of national and local studies has shown this to be the case. In particular, the 2003 UK Children's Dental Health Survey highlighted a lower level of consent than previous surveys, amongst both schools and students within them. ${ }^{4}$ In addition, for the first time in a national survey, children actively refused to participate. Recruitment of children as subjects for the dentists' training and calibration also proved problematic.

A particular example that has highlighted this dilemma is a follow-up study of 12-year-old children in two Somerset schools, first visited by Professor Anderson more than 40 years ago and at subsequent intervals. These studies were among the first to report the falling prevalence of dental caries in children. Over this period, the approach to obtaining consent changed from one where no written consent was required to the most recent, where ethical approval necessitated consent from both parent and child. Anderson $^{5}$ drew attention to the impact of changing from negative to positive consent, as a result of ethical committee guidance. In both the 1982 and 1988 surveys, 'all 12-year-old children who were present in the school were examined'. ${ }^{6,7}$ However, in 1993, when positive consent was required, only $78 \%$ of the eligible children were examined. ${ }^{5}$ further difficulties in recruiting children; mainly due to the issue of dual positive consent (from both parent and child) required by the ethical committee, in addition to factors reflecting the changing management and responsibilities of schools. ${ }^{8,9}$ Of a total of 414 children aged 12 years, only 202 were examined (49\%). Around one third of the consent forms were not returned at all, despite two mailings. Additionally, 14\% of the sample (60 subjects) actively refused to participate. The diagnostic criteria from previous studies were used, with some additions to allow comparison with the results of the 2003 UK Children's Dental Health Survey. ${ }^{10}$ Additional criteria were included to allow an estimate of the experience of trauma, tooth wear, orthodontic appearance and treatment. ${ }^{4}$ Table 1 shows the findings for caries prevalence. There were no statistically
A follow-up study in 2004 indicated significant differences in caries prevalence rates between the 1993 and 2004 studies. Including visible non-cavitated lesions in the analysis produced higher estimates of decay experience, but the difference was also not statistically significant.

Table 2 shows the prevalence of other conditions. The prevalence of children with obviously traumatised maxillary incisors was low at 5.9\%. Nearly $10 \%$ of children were wearing an orthodontic appliance when examined, $13.9 \%$ had an incisor overjet in excess of $5 \mathrm{~mm}$ and just over a quarter were judged to have an Index of Orthodontic Treatment Need Aesthetic Component of six or greater. Nearly half the children were judged to have tooth wear, involving enamel only, or enamel and dentine affecting their maxillary incisors.

This study supports the prevailing view that dental caries prevalence in children, whilst having reduced substantially over the past 40 years, is no longer reducing. The prevalence of tooth wear affecting at least enamel at the age of 12 years could be higher than the prevalence of dental caries. However, as only $49 \%$ of the eligible children were examined, the impact of these results is diminished and it is disappointing that such an important series of studies has ended with this result.

The impact of positive consent on surveys would seem to be significant and this has major implications for the planning and executing of epidemiological surveys and school screenings in the future. There is a need to be creative when recruiting children from schools, using local knowledge and contacts and ensuring that survey plans fit in with the school's agenda. The debate 
around the use of positive consent will no doubt continue, particularly in light of recent Department of Health advice to PCTs regarding measuring and monitoring obesity in schoolchildren, which indicates that negative consent is sufficient for population monitoring. ${ }^{11}$ This is at odds with the dental advice and we hope that systems will be developed to reduce the impact of the consent process on participation rates for surveys involving non-invasive dental examinations.
1. Department of Health. Health reform in England: update and commissioning framework. Gateway reference 686513 July 2006.

2. NHS Management Executive. Surveys undertaken by the British Association for the Study of Community Dentistry (BASCD). Letter to District General Managers 12 May 1992

3. Department of Health. Consent for school dental inspections and dental epidemiological surveys. Gateway reference 667326 May 2006

4. Pendry L, Lashkari G, Bewley H. Technical Report: 2003 Children's Dental Health Survey ONS, 2004

5. Anderson R J. Changes in dental caries experience of 12-year-old children in two Somerset schools: a review after an interval of 30 years. Br Dent J 1995: 179: 125-129.

6. Anderson R J. The changes in dental caries experience of 12 -year-old school children in two
Somerset schools. Br Dent J 1984; 157: 20-22.

7. Anderson $\mathrm{R} \mathrm{J}$. The changes in dental caries experience of 12-year-old schoolchildren in two Somerset schools. A review after an interval of 25 years. Br Dent J 1989; 167: 312-314.

8. Department for Education and Skills. White Paper: Schools achieving success. http://www.dfes.gov. uk/achievingsuccess/images/schoolsachievingwhitepaper.pdf. Accessed 18/8/06.

9. Education Act 2002. http://www.opsi.gov.uk/acts/ acts2002/ukpga_20020032_en.pdf. Accessed 18/8/06.

10. Pitts N, Harker R. Obvious decay experience. Children's dental health in the United Kingdom 2003. London: National Statistics, 2005.

11. Department of Health. Measuring childhood obesity: guidance to primary care trusts. Gateway reference 5990 (ROCR/OR/0027/FT6/009). 2006. 